\title{
Comparative Assessment of Maximum Voluntary Bite Force and Electromyography of Masseter Muscle Pre- and Post-oral Rehabilitation in Children between 3 and 14 Years of Age: An In Vivo Study
}

\author{
Devanshi N Mehta ${ }^{1}$, Bhavna Dave ${ }^{2}$
}

\begin{abstract}
Aim: The aim of the study was the assessment of maximum voluntary bite force (MVBF) and electromyography (EMG) of masseter muscle preand post-oral rehabilitation in children between 3 years and 14 years of age.

Materials and methods: The study population consisted of 60 children aged 3-14 years of age divided into 3 groups of 20 each based on the dentition. The MVBF and the EMG of the masseter muscle were recorded pre- and post-oral rehabilitation.

Results: The MVBF in phase I and II for right side was found to be 32.32 and $36.59 \mathrm{~kg}$, respectively, and for the left side was found to be 32.24 and $36.53 \mathrm{~kg}$, respectively, which was highly significant. Electromyography of masseter muscle for both the phases was found to be $283.87 \mu \mathrm{V}$ in phase I and $329.64 \mu \mathrm{V}$ in phase II with a high significance.

Conclusion: A significant improvement was observed post-oral rehabilitation in the MVBF and the electromyographic activity of the masseter muscle. Maximum voluntary bite force was seen more in males as compared to females with no side predilection. Hence, the effect of dental caries on bite force and masticatory muscle activity was established.
\end{abstract}

Keywords: Bite force, Electromyography, Masseter muscle, Oral rehabilitation.

Journal of South Asian Association of Pediatric Dentistry (2020): 10.5005/jp-journals-10077-3052

\section{INTRODUCTION}

Occlusal bite force is one of the indicators of the functional state of the masticatory system that results from action of jaw elevator muscles modified by the craniofacial biomechanics (Bakke, 2006). ${ }^{1}$ The masticatory force and the efficiency with which it functions is the masticatory performance determined by the occlusal contact area and number of teeth that function. To maintain eating habits, complete nutritional requirements, and stimulate the overall growth and development, adequate masticatory ability is important. A reduced mastication may weaken the masticatory muscle activity and their efficiency. ${ }^{2}$ Bite force measurement has been widely used to understand the workings of mastication. A bite force device (gnathodynamometer) helps to understand an individual's bite force and surface electromyography (EMG) studies the electrophysiological behavior of the skeletal muscle in a noninvasive manner.

Many physiological and morphological variables, such as craniofacial morphology, age, gender, periodontal support of the teeth, height and body weight, temporomandibular disorders, pain, and dental status, contribute to affect the bite force and masticatory muscle activity. Among these, dental caries is the most common to affect the number of well-functioning teeth that has a high prevalence all over the world, particularly in developing countries. The prevalence of dental caries in the place of the study, i.e., Vadodara city was found as high as $69.12 \%$ in children. ${ }^{3}$ Based on the hypothesis that dental caries at extensive levels leads to causation of pain, which might compromise the state of mastication in children in turn reducing masticatory muscle activity, this study was conducted.

\begin{abstract}
1,2Department of Pedodontics and Preventive Dentistry, KM Shah Dental College and Hospital, Sumandeep Vidyapeeth, Vadodara, Gujarat, India

Corresponding Author: Devanshi N Mehta, Department of Pedodontics and Preventive Dentistry, KM Shah Dental College and Hospital, Sumandeep Vidyapeeth, Vadodara, Gujarat, India, Phone: +91 9106708102, e-mail: dentist.dentacare@gmail.com

How to cite this article: Mehta DN, Dave B. Comparative Assessment of Maximum Voluntary Bite Force and Electromyography of Masseter Muscle Pre- and Post-oral Rehabilitation in Children between 3 and 14 Years of Age: An In Vivo Study. J South Asian Assoc Pediatr Dent 2020;3(2):54-59.
\end{abstract}

Source of support: Sumandeep Vidyapeeth

Conflict of interest: None

The aim of the study was the assessment of maximum voluntary bite force (MVBF) and EMG of masseter muscle pre- and post-oral rehabilitation in children between 3 years and 14 years of age.

\section{Materials and Methods}

The study was conducted with ethical approval from the institutional ethical review board (SVIEC/ON/Dent/BNPG14/ D15027). All the children between 3 and 14 years of age attending the OPD of Pedodontics and Preventive Dentistry were screened until a sample size of 60 was obtained meeting the selection criteria and written parental consent. The principal investigator performed a thorough intraoral examination including dental caries status using deft and decayed missing filled teeth (DMFT) index. ${ }^{4}$ 


\section{Inclusion Criteria}

- Children with flush terminal plane or mesial step molar relation in deciduous dentition (Baume's classification) and Angle's class I molar relation in mixed and permanent dentition.

- Children requiring at least 2 restorations per quadrant and not more than 2 missing teeth per quadrant.

\section{Exclusion Criteria}

- Children with any systemic diseases, open bite or cross bite and temporomandibular joint (TMJ) disorders were excluded.

- The sample group was divided into 3 groups of 20 each based on the dentition, i.e., primary dentition (group I), mixed dentition (group II), and permanent dentition (group III).

The study was a double-blinded study, blinding the co-investigator and the statistician. The patient selection and oral rehabilitation was performed by the principal investigator and the data recordings performed by calibrated co-investigator to avoid bias. The study was divided into two phases namely, P1, i.e., the clinical evaluation, MVBF determination and the EMG pretreatment for all the patients and $\mathrm{P} 2$, i.e., post-rehabilitation. For P1, MVBF was recorded for each child using a custom-made gnathodynamometer (Emertech Electronics Systems) (Fig. 1). All

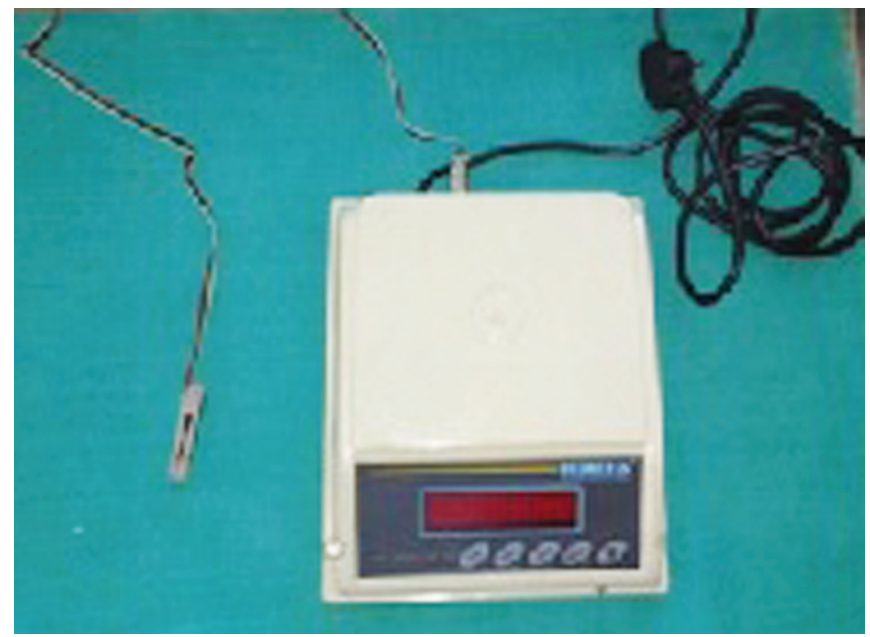

Fig. 1: Gnathodynamometer

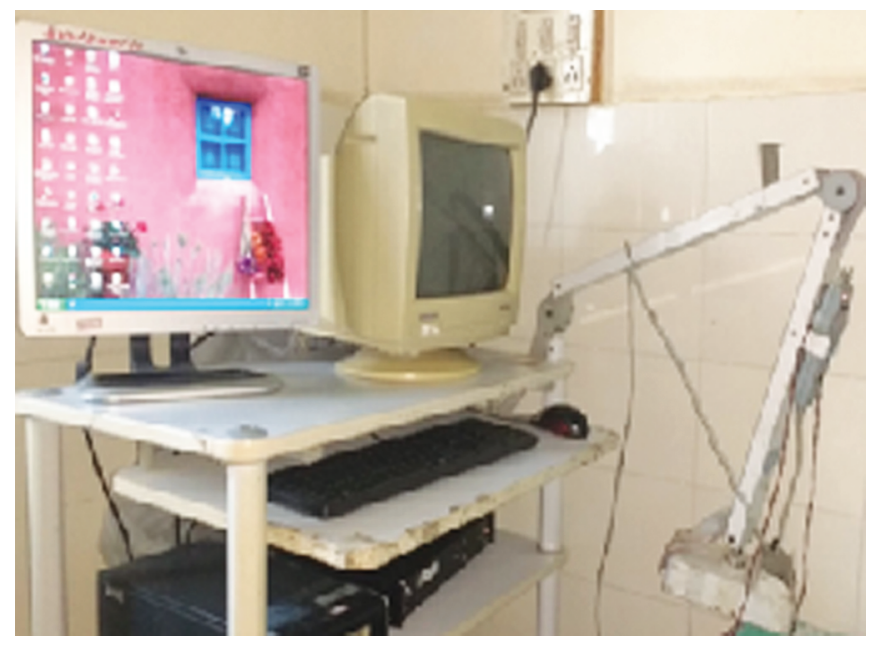

Fig. 3: Surface electromyography machine patients were seated in the dental chair with the head positioned so as the Frankfort horizontal plane would be parallel to the floor $^{1}$ (Fig. 2). The patients were asked to bite on the bite fork when placed in the oral cavity in the non-affected molar region (2nd primary molar in primary dentition and 1st permanent molar in mixed and permanent dentitions). For each patient, a series of three consecutive readings was noted with a rest period of 1 minute to prevent muscle fatigue. Mean of the three readings was taken. Surface EMG was performed using RMS Aileron EMG series EMG/NCV/EP System (Fig. 3). Right and left masseter muscles were the target muscles in the study, which were recorded bilaterally with the use of a single-electrode pair. The chewing efficiency is guaranteed by the force exerted on the contraction of the masseter muscle teeth contact which guided the selection of the muscle. ${ }^{5}$ The main mass of the muscle (approximately $2 \mathrm{~cm}$ above the angle of the mandible) was palpated manually for the placement of the first electrode while asking the patient to clench maximally and the second electrode was placed $1.0 \mathrm{~cm}$ apart and parallel in orientation from the first ${ }^{6}$ (Figs 4 to 6). The area was disinfected using surgical spirit BP prior to the placement of ultrasonography gel-coated electrodes. ${ }^{7}$ Electromyography was recorded continuously for 1 minute for each muscle (right and left) in terms of microVolt (Figs 7 and 8).

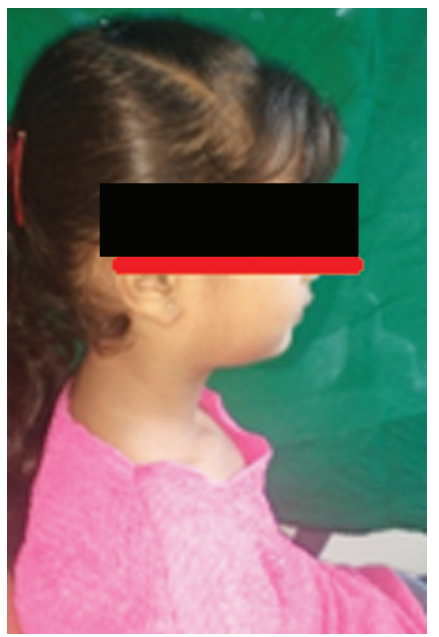

Fig. 2: Position of the head while recording the bite force

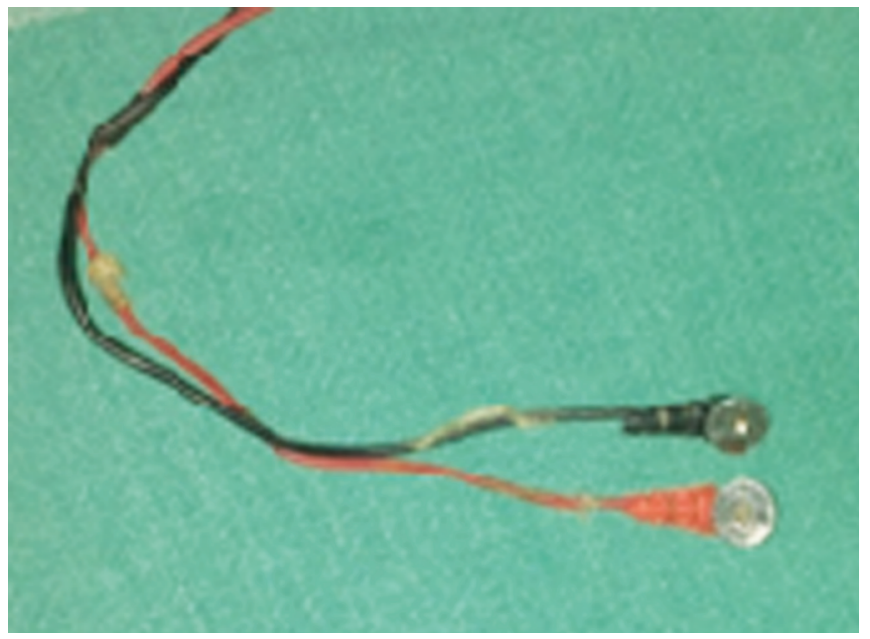

Fig. 4: Surface electrodes 


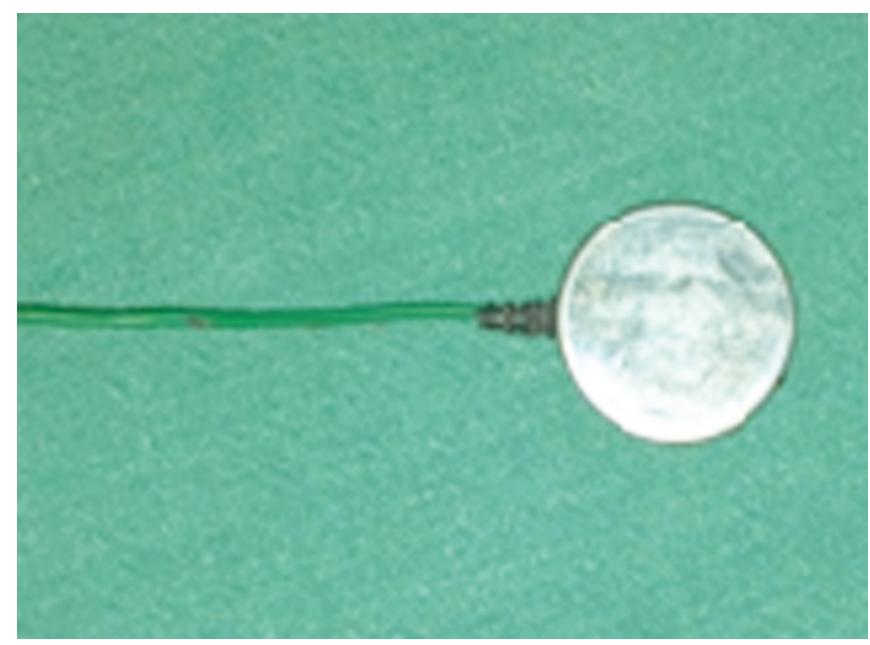

Fig. 5: Electrode for the skin

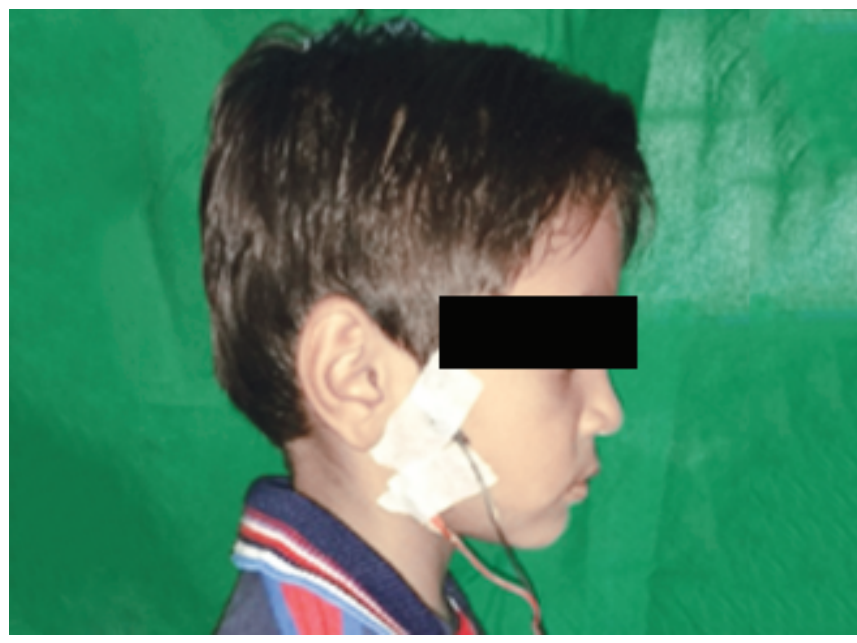

Fig. 6: Placement of electrodes for recording surface electromyography

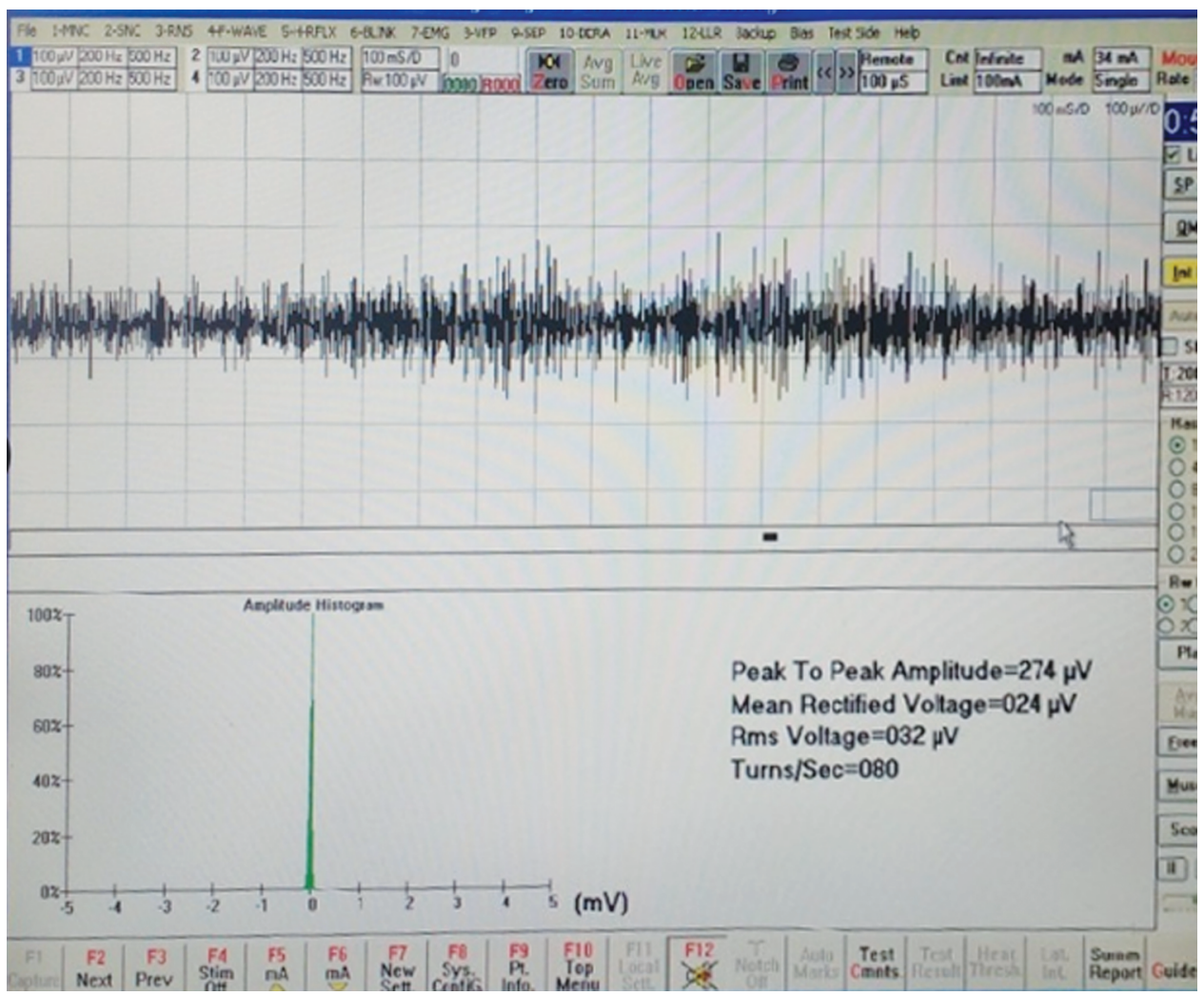

Fig. 7: Electromyographic activity of masseter muscle in P1

Full mouth rehabilitation included restorations of affected teeth performed using glass ionomer cement (GC Gold Label Type 2 Universal $\mathrm{GIC}$ ) in primary teeth and composite resin restoration (3M Filtek Universal Restorative). All the restorations were finished and polished. Recordings for P2 were taken after an interval of a week to ensure well adjustment to the rehabilitation and accurate readings (Flowchart 1).

\section{Results}

The study included 36 males and 24 females. Males showed higher MVBF as compared to females. The electromyographic activity did not show such variation. The MVBF in P1 and P2 was analyzed using paired $t$ test and for right and left side was highly significant ( $p<0.001$ ) (Figs 9 and 10) showing oral rehabilitation proved to increase the bite force.

A statistical significance was observed (Table 1) in all the three dentitions.

The EMG of masseter muscle for both the phases using paired t test was found to be $283.87 \mu \mathrm{V}$ in $\mathrm{P} 1$ and $329.64 \mu \mathrm{V}$ in $\mathrm{P} 2$ on the right side with a highly significant $p$ value $(<0.001)$ and for $\mathrm{P} 1$ and $\mathrm{P} 2$ of the left side which was $286.68 \mu \mathrm{V}$ in P1 and $335.33 \mu \mathrm{V}$ in P2 with a highly significant $p$ value $(<0.001)$. However, no difference was observed in right and left sides. 


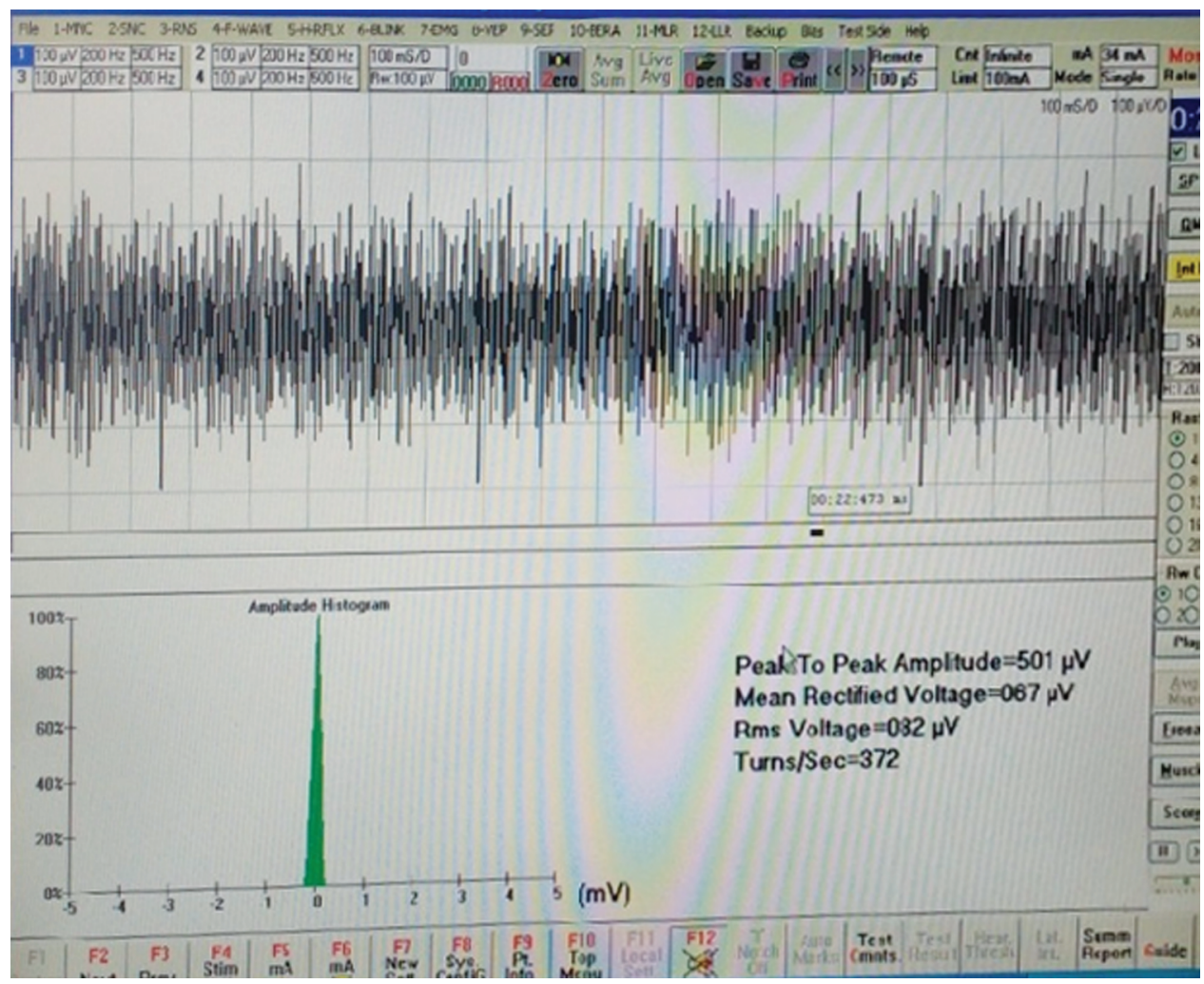

Fig. 8: Electromyographic activity of masseter muscle in P2

Flowchart 1: CONSORT diagram

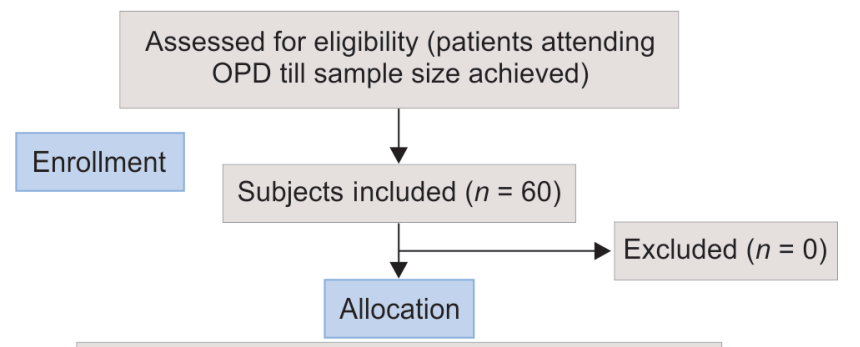

Allocated to three subgroups based on dentition

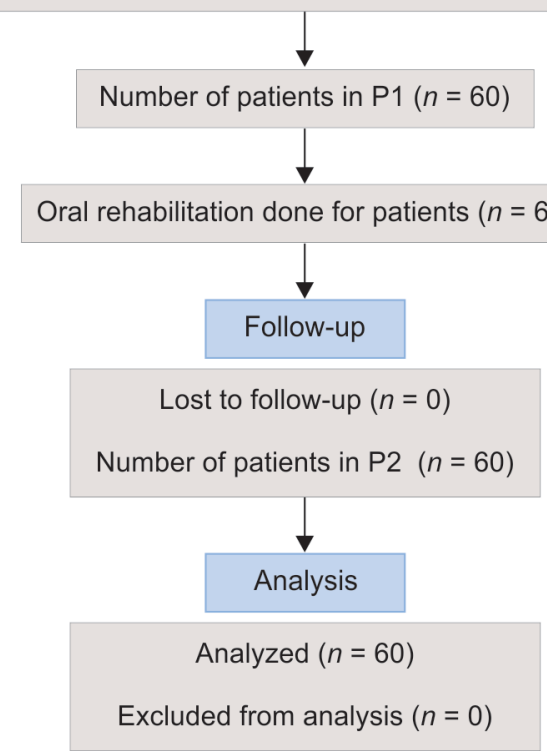

The comparison of the mean difference of EMG of masseter muscle in P1 and P2 for both the sides among all the three groups using analysis of variance (ANOVA) test was found to be highly significant ( $p<0.001)$ (Figs 11 and 12).

The significant difference observed by ANOVA test paved way for further application of the Tukey's post hoc analysis for the same. This analysis stated that the intergroup comparison between groups I and II was significant, the comparison between groups II and III was significant but the comparison between groups I and III was not significant (Table 2).

\section{Discussion}

For children and their parent's awareness of the positive effects of oral rehabilitation on the chewing efficiency and muscle functioning, this study was conducted. To cover all the dentitions and variations, an age group of 3-14 years was included in the study. In this study, both the methods to determine the bite force, i.e., directly using a bite fork and indirectly by the electromyographic activity of the surface elevator muscles of the mandible were used and a correlation was made. ${ }^{8}$ The readings were calibrated in terms of kilograms $(\mathrm{kg})$ for the better understanding and communication.

This study showed a difference in the bite force in the two phases which signifies improvement of masticatory ability by restoration of dental caries similar to the study performed by Subramaniam and Girish Babu ${ }^{9}$ in primary dentition. Bonakdarchian et al., 2009, Abu Alhaija et al., 2010, and Palinkas et al., 2010 also noted effect of dental caries status along with other factors, such as age, gender, craniofacial morphology, periodontal support of teeth, and temporomandibular disorders to affect the MVBF in children. A positive relationship between MVBF and increasing dentition 
Table 1: Mean difference in P1 and P2 in MVBF in group I, II, and III

\begin{tabular}{llllll}
\hline & & \multicolumn{4}{c}{ Mean } \\
\cline { 3 - 5 } & & $I$ & $I I$ & III value \\
\hline Pair 1 & Right pre-MVBF & 18.6780 & 33.1295 & 45.1730 & $<0.001^{* * *}$ \\
& Right post-MVBF & 22.5833 & 37.1667 & 50.0250 & \\
Pair 2 & Left pre-MVBF & 18.7267 & 33.0083 & 45.0083 & \\
& Left post-MVBF & 22.6267 & 37.2000 & 49.7867 & \\
\hline
\end{tabular}

**Highly significant

Table 2: Comparison of the mean difference of MVBF in P1 and P2 for both the sides among all the three groups using ANOVA test

\begin{tabular}{llll}
\hline & & Right side & Left side \\
\cline { 3 - 4 } Group & No. of samples & Mean $(S D)$ & Mean $(S D)$ \\
\hline Group I & 20 & $3.90(0.9)$ & $3.90(1.1)$ \\
Group II & 20 & $4.03(2.0)$ & $4.19(2.2)$ \\
Group III & 20 & $4.85(0.7)$ & $4.77(1.2)$ \\
$p$ value & - & 0.068 & 0.237 \\
\hline
\end{tabular}

$p$ value not significant

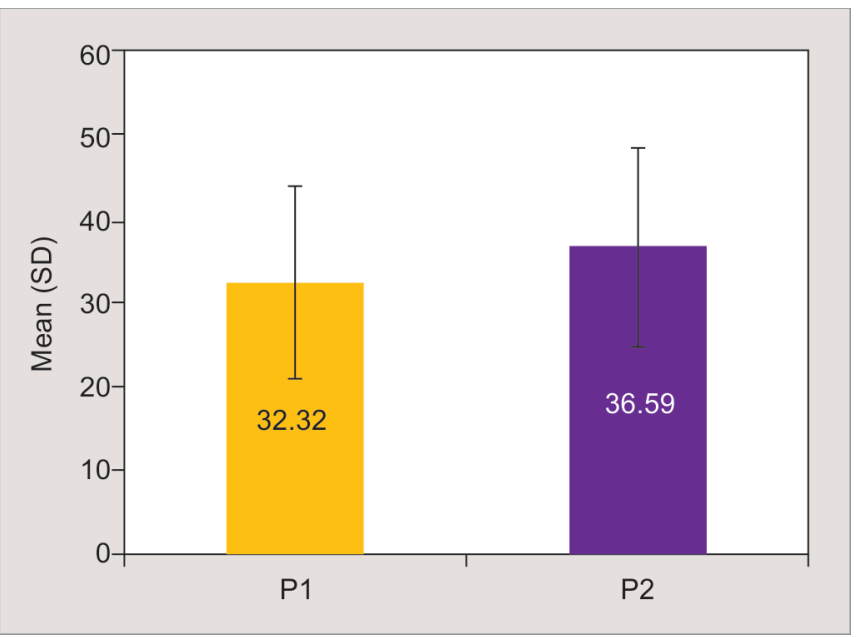

Fig. 9: Comparison of MVBF in P1 and P2 for right side

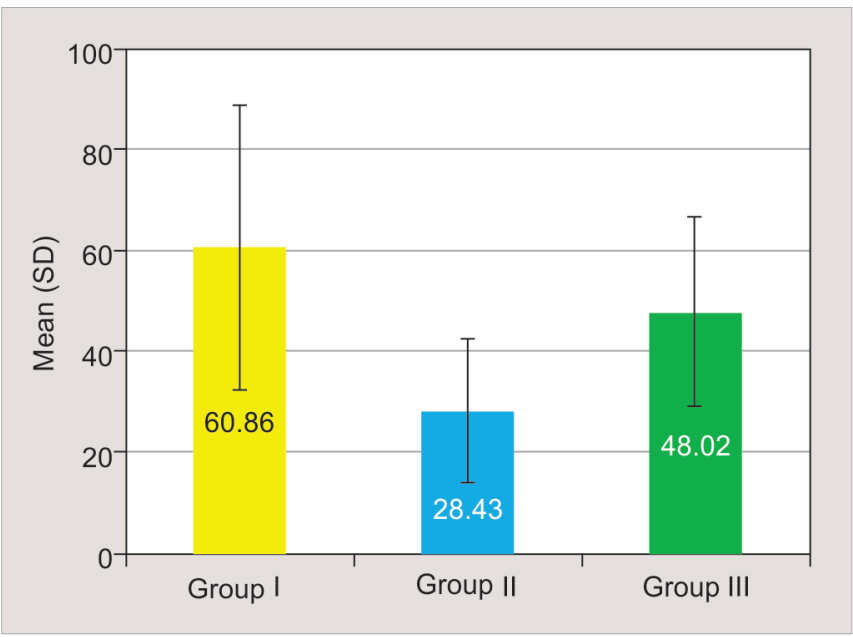

Fig. 11: Comparison of the mean difference of electromyography of masseter muscle in $\mathrm{P} 1$ and $\mathrm{P} 2$ for right side among all the three groups

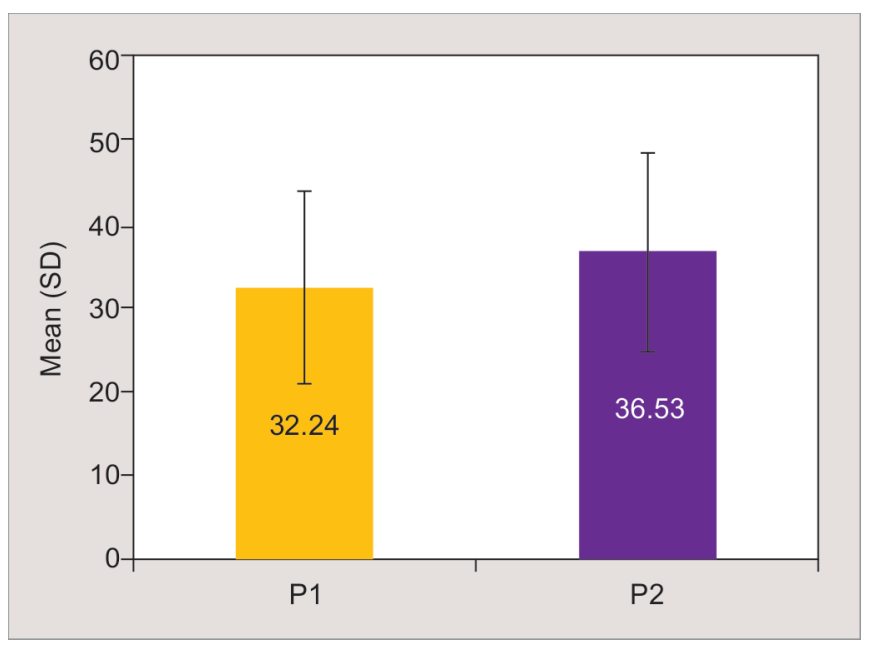

Fig. 10: Comparison of MVBF in P1 and P2 for left side

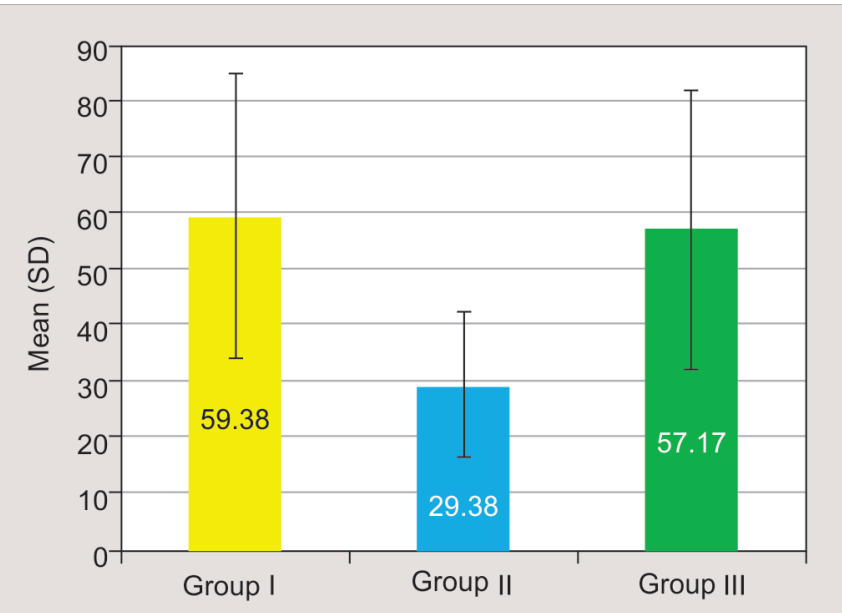

Fig. 12: Comparison of the mean difference of electromyography of masseter muscle in P1 and P2 for left side among all the three groups

stages was observed like the study performed by Sonnesen et al., 2001 and Owais et al., 2013 in children aged $7-13$ years. ${ }^{10}$ Maximum voluntary bite force was measured in the posterior teeth because it has a greater number of occlusal contact points giving maximum force possible. ${ }^{11-14}$ In the study, we have attempted to increase the occlusal contacts by rehabilitation which according to Bakke et al. is a stronger determinant of muscle action and bite force than the number of teeth. ${ }^{15}$

The mean MVBF in the study was $48.44 \mathrm{~kg}$ in $\mathrm{P} 1$ and increased up to $54.85 \mathrm{~kg}$, which was similar to the study performed in Taiwanese 
children $^{8}$ and the values for mean MVBF for mixed dentition was parallel to the values obtained in the study performed by Braun et al., in 1996. ${ }^{2}$ Similarly, Mountain et al. stated MVBF exerted by children with primary dentition can be predicted by the deft index. ${ }^{16}$ This could be explained as the fear of pain or discomfort due to dental decay may lead to muscle force reduction. ${ }^{17}$ Moreover, like in this study, Kamegai et al. also concluded the increase in bite force with age from 3 to 14 years, in both males and females. ${ }^{18-20}$ Whereas, Wichelhaus et al. ${ }^{21}$ have found no significant gender predilection. The surface EMG technique was chosen as it was a noninvasive and easy to perform ${ }^{22-25}$ in the pediatric age group. According to Lund et al., surface electromyography (SEMG) activity has been known to be useful in noting the changes in muscle function before and after therapeutic interventions which serves the objectives of this study. ${ }^{26}$ As in the present study, Garrett et al. also noted an increase in EMG activity of the masseter muscle with increase in the bite force. ${ }^{27}$

This study aimed at a futuristic approach to help educate the parents the dental caries status of their children and motivate them to undergo full mouth rehabilitation. This study will help the clinician restore the complete oral health of the child leading to less dental and TMJ problems in later stages of life.

\section{Limitations}

- The study was performed in a small population confined to a particular region, hence its applicability to the entire population might be questionable.

- The depth or severity of the carious lesions was not recorded to limit the variability in the study.

\section{Conclusion}

A significant increase or improvement post-oral rehabilitation in MVBF and the electromyographic activity of the masseter muscle was observed. The MVBF was more in males as compared to females in both phases with no significant difference in the electromyographic activity. Both parameters did not show a side predilection.

\section{References}

1. Singh S, Sandhu N, Kashyap R. A study of bite force and various variables in children segregated by Angle's classification. Int J Clin Pediatr Dent 2012;5(2):118-123. DOI: 10.5005/jp-journals10005-1148.

2. Braun S, Hnat WP, Freudenthaler JW, et al. A study of maximum bite force during growth and development. Angle Orthod 1996;66(4): 261-264.

3. Joshi N, Sujan SG, Joshi K, et al. Prevalence, severity and related factors of dental caries in school going children of Vadodara city -an epidemiological study. J Int Oral Health 2013;5(4):40-48.

4. World Health Organization. Oral health surveys: basic methods. 4th ed., Geneva 1997 https://apps.who.int/iris/handle/10665/41905.

5. Nascimento GKBO, da Cunha DA, de Lima LM, et al. Surface electromyography of the masseter muscle during chewing: a systematic review. Rev CEFAC 2012;14(4):725-731. DOI: 10.1590/S151618462012005000042.

6. Cacioppo JT, Tassinary LG, Berntson GG. The skeletomotor system: surface electromyography. Handbook of Psychophysiology. 2nd ed., Cambridge University Press; 2000.

7. Konrad $\mathrm{P}$, The $A B C$ of EMG: A Practical Introduction to Kinesiological Electromyography Version 14. Noraxon U.S.A, Inc; 2006.
8. Koc D, Dogan A, Bek B. Bite force and influential factors on bite force measurements: a literature review. Eur J Dent 2010;4(2):223-232. DOI: 10.1055/s-0039-1697833.

9. Subramaniam P, Girish Babu KL, Ifzah. Effect of restoring carious teeth on occlusal bite force in children. J Clin Pediatr Dent 2016;40(4):297300. DOI: 10.17796/1053-4628-40.4.297.

10. Sghaireen MG, Al-Omiri MK, Patil S, et al. Maximum bite force for children on primary and permanent teeth: within subject comparison. Eur Sci Jrnl 2014;10(30):166-173.

11. Bakke M. Bite force and occlusion. Semin Orthod 2006;12(2):120-126. DOI: 10.1053/j.sodo.2006.01.005.

12. Su CM, Yang YH, Hsieh TY. Relationship between oral status and maximum bite force in preschool children. J Dent Sci 2009;4(1):32-39. DOI: 10.1016/S1991-7902(09)60006-4.

13. Hidaka O, Iwasaki M, Saito M, et al. Influence of clenching intensity on bite force balance, occlusal contact area, and average bite pressure. J Dent Res 1999;78(7):1336-1344. DOI: 10.1177/00220345990780070801.

14. Subramaniam P, Girish Babu KL, Ifzah. Evaluation of occlusal forces in different stages of children-an exploratory study. S J Oral Sci 2018;5(1):11-17. DOI: 10.4103/sjos.SJOralSci_52_17.

15. Bakke $M$, Holm $B$, Jensen $B L$, et al. Unilateral, isometric bite force in 8-68-year-old women and men related to occlusal factors. Scand J Dent Res 1990;98(2):149-158. DOI: 10.1111/j.1600-0722.1990. tb00954.x.

16. Mountain G, Wood D, Toumba J. Bite force measurement in children with primary dentition. Int J of Paediatr Dent 2011;21:112-118. DOI: 10.1111/j.1365-263X.2010.01098.x.

17. Tsai HH. Maximum bite force and related dental status in children with deciduous dentition. J Clin Pediatr Dent 2004;28(2):139-142. DOI: 10.17796/jcpd.28.2.j42870t47q4n1715.

18. Kamegai T, Tatsuki T, Nagano $H$, et al. A determination of bite force in northern Japanese children. Eur J Orthod 2005;27(1):53-57. DOI: 10.1093/ejo/cjh090.

19. Roldán SI, Restrepo LG, Isaza JF, et al. Are maximum bite forces of subjects 7 to 17 years of age related to malocclusion? Angle Orthod 2016;86(3):456-461. DOI: 10.2319/051315-323.1.

20. Ferrario VF, Sforza C, Serrao G, et al. Single tooth bite forces in healthy young adults. J Oral Rehabil 2004;31(1):18-22. DOI: 10.1046/j.0305182X.2003.01179.X.

21. Wichelhaus A, Hüffmeier S, Sander FG. Dynamic functional force measurements on an anterior bite plane during the night. J Orofac Orthop 2003;64(6):417-425. DOI: 10.1007/s00056-0030316-5.

22. Gaur A, Sujan SG, Katna V. The oral health status of institutionalized children that is, juvenile home and orphanage home run by Gujarat state government, in Vadodara city with that of normal school children. J Indian Soc Pedod Prev Dent 2014;32(3):231-239. DOI: 10.4103/0970-4388.135833.

23. Sommerfeld LS, Machoy M, Woźniak K. The diagnostic value of electromyography in identifying patients with pain-related temporomandibular disorders. Front Neurol 2019;10:180-187. DOI: 10.3389/fneur.2019.00180.

24. Woźniak K, Piątkowska D, Szyszka-Sommerfeld L, et al. The impact of functional appliances on muscle activity. Med Sci Monit 2015;21:246253. DOI: 10.12659/MSM.893111.

25. Gonzalez Y, Iwasaki LR, McCall Jr WD, et al. Reliability of EMG activity vs bite-force from human masticatory muscles. Eur J Oral Sci 2011;119(3):219-224. DOI: 10.1111/j.1600-0722.2011. 00823.x.

26. Klasser GD, Okeson JP. The clinical usefulness of surface electromyography in the diagnosis and treatment of temporomandibular disorders. J Am Dent Assoc 2006;137(6):763-771. DOI: 10.14219/jada.archive.2006.0288.

27. Garrett FA, Angelone L, Allen WI. The effect of bite opening, bite pressure, and malocclusion on the electrical response of the masseter muscles. Am J Orthod 1964;50:435-444. DOI: 10.1016/00029416(64)90206-4. 